\section{Step-down passive avoidance: CER or specific avoidance?}

\author{
J. D. BARCIK
}

Windham College, Putney, Vt. 05346

Specific response inhibition vs conditioned emotional response (CER) contributions to this passive avoidance performance was tested by providing footshock either as a result of stepping down or independent of this response. Both response-contingent and noncontingent components were involved in this passive avoidance performance. However, the response-contingent component was the more important. A delay-of-punishment gradient was obtained which supported this conclusion. Earlier conclusions regarding CER incubation in this task were not supported.

Passive avoidance performance has been interpreted by Spevack \& Suboski (1969) to be a result of CER incubation, not a specific response-punishment contingency. The CER becomes conditioned to apparatus cues such that after $24 \mathrm{~h}$, when $S$ is again placed in the apparatus, a generalized behavioral suppression develops (CER). Thus, when $S$ passively avoids, it is a result of CER, not a specific response inhibition. However, as Dawson (1971) has pointed out, it is not clear when CER plays a major role in avoidance performance. Experimental distinction between response-contingent punishment and CER contributions to passive avoidance performance must be made in order to establish which component is of primary importance.

Dawson (1971) has further suggested that workable criteria for distinguishing between the CER and the specific avoidance response are lacking. However, Spevack \& Suboski (1967) did provide an experimental distinction in a barpress situation by presenting footshock either as a consequence of a barpress or while $S$ was at the foodcup, i.e., response-contingent or noncontingent punishment. Both groups exhibited fear, which suggested that CER was a very important factor in barpress suppression.

The presentation of footshock in a step-down passive avoidance task also may be either response-contingent or noncontingent. If CER develops and is the mechanism underlying this passive avoidance, this contingency should be unimportant. The CER will be produced by apparatus cues independent of the step-down response, and $S$ should avoid because of a generalized behavioral suppression. However, if the response-punishment contingency is more important than the CER component, the performance of the response-contingent $\mathrm{Ss}$ should be superior to that of the noncontingent Ss. Furthermore, if the response-punishment contingency is of primary importance, then delaying the punishment should produce a delay-of-punishment gradient. Thus, the following experiment was completed.

\section{SUBJECTS}

A total of 50 Charles River CD male rats, approximately $120-160$ days old, served as Ss. All Ss were housed in access to food and water.

APPARATUS

The step-down apparatus reported by Chorover \& Schiller (1965) was modified such that the 5 -in.-square platform was placed in a corner with a 7 -in.-high wall affixed such that the step-down response could occur in only one direction. Footshock (FS) was delivered by a Grason-Stadler E1064GS shock generator and scrambler. Step-down latency (SDL) was recorded by a Lafayette Instruments multichoice reaction timer in .01 sec. The delay intervals were timed by a Hunter decade timer. PROCEDURE

The $50 \mathrm{Ss}$ were assigned randomly to five groups of 10 Ss each. All shocked groups received a $2.5-\mathrm{mA}$ 3-sec FS. The zero-delay response-contingent group received FS immediately upon stepping down. The delayed response-contingent groups received FS either 10 or 30 sec after stepping down. The $S s$ of the noncontingent group were restrained on the platform for approximately 1 sec and then placed directly on the grid floor in front of the platform, where they received FS. Since the SDL for the zero-delay $S s$ was approximately 1 sec, the response-contingent and the noncontingent $S s$ received FS at approximately the same time after being introduced into the apparatus. The area of the grid floor where FS began was also the same for these two groups, i.e., immediately in front of colony cages and were allowed ad lib the platform. The nonshocked control Ss were allowed to step down without FS. All Ss were tested $24 \mathrm{~h}$ after the first trial. If $\mathbf{S}$ did not step down within $60 \mathrm{sec}$, the trial was terminated and the SDL was recorded as 60 sec. RESULTS

Figure 1 summarizes the percentage of Ss avoiding (SDL $>30 \mathrm{sec}$ ) for all groups on Trial 2. The SDL difference between the zero delay and the noncontingent groups was statistically significant (Mann-Whitney $U=16.5$, $\mathrm{p}<.01$ ). The SDL difference between the noncontingent and the nonshocked control groups was also statistically significant (Mann-Whitney $\mathrm{U}=16.5, \mathrm{p}<.01$ ). The delivery of FS independent of the step-down response produced an increase in SDL. However, the increase in SDL was more obvious when the punishment was response contingent.

A chi square of $k$-independent shocked groups using number of Ss avoiding indicated that the noncontingent, $0-, 10-$, and 30 -sec delay groups differed significantly $\left(x^{2}=11.33\right.$, df $\left.=3, \quad p<.02>.01\right)$. The analysis of the response-contingent group differences (excluding the noncontingent group) also indicated that the differences were statistically significant $\left(x^{2}=6.67, \mathrm{df}=2, p<.05\right.$ $>.01)$. The avoidance performance declined with increasing delay intervals, which demonstrated a delay -of-punishment gradient. DISCUSSION

The present results clearly indicate that when punishment in this step-down task was not response contingent, passive avoidance performance was poor. This suggests that CER was not the major determinant of this passive avoidance. However, since this group did differ

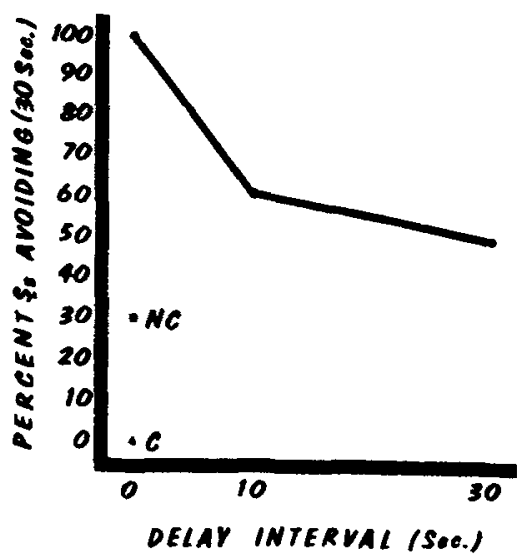

Fig. 1. Percentage of Ss avoiding (SDL > $30 \mathrm{sec}$ ) for all groups on Trial 2. 
from a nonshocked control group, it is likely that CER did develop and did lead to passive avoidance for some $S s$. This result is in only mild support of Spevack \& Suboski (1969), who have suggested that CER is the major mechanism underlying this kind of passive avoidance.

When punishment was response contingent and immediate, passive avoidance performance was high. All Ss avoided. This result indicates that the response-punishment contingency was an important component of this passive avoidance performance. This result is supported by earlier work by Barcik \& Ellis (1971) which indicated that intention step-down responses were specifically inhibited. Generalized behavioral suppression (freezing) most frequently followed such an intention step-down but did not continue for the duration of the avoidance criterion. Thus, a specific avoidance response was learned and was more important to this passive avoidance than was CER. This result is inconsistent with the work of Spevack \& Suboski (1967), which indicated that the punishment contingency was unimportant, i.e., the noncontingent group exhibited as much fear as the response-contingent group in that barpress situation.

The decline in avoidance performance with increasing delay between the step-down response and footshock further supports the suggestion that a specific response-punishment contingency was learned in this task. If a CER were the major component of this avoidance performance, it should have made no difference when the footshock was presented. Thus, avoidance performance should have been the same for all delay groups via generalized behavioral suppression (CER). Since this was not the case, a CER interpretation of this passive avoidance was not supported. Rather, the delay-of-punishment gradient found in this experiment supports the conclusion that specific response-punishment association was primarily responsible for the avoidance performance. Thus, the suggestion by Spevack \& Suboski (1969) that passive avoidance performance is the result of CER was not supported by the present results.

\section{REFERENCES}

BARCIK, J. D., \& ELLIS, K. R. Passive avoidance: An analysis of behaviora inhibition. Paper presented at the Animal Behavior Society meetings, Logan, Utah. June 1971 .

CHOROVER, S. L., \& SCHILLER, P. H. Short-term retrograde amnesia in rats. Journal of Comparative \& Physiological Psychology, 1965, 59, 73-78.

DAWSON, R. G. Retrograde amnesia and conditioned emotional response incubation reexamined. Psychological Bulletin, 1971, 75, 278-285.

SPEVACK, A. A., \& SUBOSKI, M. D. A confounding of conditioned suppression in passive avoidance: ECS effects. Psychonomic Science, 1967, 9, 23-24.

SPEVACK, A. A., \& SUBÓSKI. M. D Retrograde effects of electroconvulsive shock on learned responses. Psychological Bulletin, 1969, 72, 66-76. 